ISSN: 1907-9931 (print), 2476-9991 (online)

\title{
ANALISIS KONDISI KESEHATAN TERUMBU KARANG DENGAN MENGGUNAKAN SOFTWARE CPCE (CORAL POINT COUNT WITH EXCEL EXTENSIONS) DI TAMAN NASIONAL KOMODO, NUSA TENGGARA TIMUR CORAL REEF HEALTH ANALYSIS WITH CPCE SOFTWARE (CORAL POINT COUNT WITH EXCEL EXTENSIONS) AT KOMODO NATIONAL PARK, EAST NUSA TENGGARA
}

\author{
Cut Fitri Malinda ${ }^{1^{*}}$, Oktiyas Muzaky Luthfi ${ }^{1}$, Tri Aryono Hadi ${ }^{2}$ \\ ${ }^{1}$ Program Studi IImu Kelautan, Fakultas Perikanan dan Ilmu Kelautan, Universitas Brawijaya, Jl. \\ Veteran Malang, Jawa Timur 65145, Indonesia \\ ${ }^{2}$ Pusat Penelitian Oseanografi, LIPI JI. Ancol Timur, Jakarta Utara 14430, Jakarta, Indonesia
}

${ }^{*}$ Corresponden author e-mail: cutfm1@gmail.com

Submitted: 18 January 2020 / Revised: 07 Agustus 2020 / Accepted: 11 August 2020

http://doi.org/10.21107/jk.v13i2.6464

\begin{abstract}
Coral reef is one of the coastal ecosystems that has an important role as a place to look for food, shelter, and breeding grounds for other biotas. Besides, the ecological aspects of coral reefs as a coastal protectors from waves and abrasion. CPCe (Coral Points Count with Excel extension) is used to observe or monitoring reefs ecpsystems. The photo that will be taken using the Underwater Photo Transect (UPT) method from 9 observation stations in Komodo's Waters will be used as this research database. The photos consists of 50 photos for each station. Photos were taken, assuming can represent the Komodo Waters. Each photo processed in the CPCe, using 30 random points. The results showed the highest hard coral percentage cover at station 2 is $58.36 \%$, while the lowest hard coral percentage cover at station 7 is $5.07 \%$. Hard coral cover in Komodo waters has a percentage of $23.62 \%$ categorized in the damaged state.
\end{abstract}

Keywords: coral reef; CPCe, Komodo Island

\begin{abstract}
ABSTRAK
Terumbu karang merupakan salah satu ekosistem pesisir yang memiliki peranan penting sebagai tempat mencari makan, tempat tinggal, dan tempat berkembang biak biota lain. Selain itu, aspek ekologis terumbu karang yaitu sebagai pelindung pantai dari terpaan gelombang dan abrasi. CPCe (Coral Point Count with Excel extensions) digunakan untuk mengamati atau memantau terumbu karang. Data yang digunakan adalah hasil foto yang diambil menggunakan metode Underwater Photo Transect (UPT) dari 9 stasiun pengamatan di Perairan Komodo. Foto tersebut terdiri dari 50 foto untuk setiap stasiunnya. Foto yang diambil dengan asumsi dapat mewakili stasiun yang digunakan. Setiap foto yang diolah dalam CPCe digunakan 30 titik acak. Hasil penelitian menunjukkan tutupan karang keras tertinggi terdapat di stasiun 2 sebesar 58,36\%, sedangkan tutupan karang keras terendah pada stasiun 7 dengan nilai sebesar 5,07\%. Tutupan karang keras di Perairan Komodo memiliki persentase sebesar 23,62\% yang termasuk dalam kategori rusak.
\end{abstract}

Kata kunci: terumbu karang, CPCe, Perairan Komodo

\section{PENDAHULUAN}

Pendataan kesehatan terumbu karang, terdapat indeks yang dijadikan standar. Indeks kesehatan terumbu karang ini berguna untuk pengelolaan terumbu karang dan ekosistem terkait. Kategori kondisi terumbu karang didasarkan pada tutupan karang keras (hard corals) yang hidup, yaitu sangat baik (excellent) $>75 \%$; baik (good) $50 \%$ - $\leq 75 \%$; cukup (fair) $25 \%$ - $\leq 50 \%$; dan jelek (poor) $\leq 25 \%$ (Hadi et al., 2018).

CPCe (Coral Point Count with Excel extensions) merupakan piranti lunak yang dikembangkan oleh NSU (Nova Southeastern 
Jurnal Kelautan, 13(2), 108-114 (2020)

University) yang digunakan untuk mengamati atau memantau terumbu karang. Piranti lunak ini dapat diunduh secara bebas. CPCe digunakan dengan menghitung jumlah titik per kategori life form per 30 titik acak yang dianggap sudah 109epresentative untuk menduga persentase tutupan kategori. Datadata yang digunakan didapat dari foto-foto bawah air yang diambil dengan menggunakan metode Underwater Photo Transect (UPT) (Giyanto et al., 2014).

Metode pemantauan kondisi terumbu karang banyak yang digunakan oleh para peneliti memiliki banyak ragam. Line Intercept Transect (LIT) merupakan metode yang dikembangkan oleh AIMS (Australian Institue of Marine Science) dengan menarik transek garis. Point Intercept Transect (PIT) sama dengan LIT namun tutupan yang dihitung dengan interval 0,5 meter. Underwater Photo Transect (UPT) merupakan metode pengambilan data yang dilakukan dengan melakukan pemotretan bawah air. Metode ini dapat mempersingkat waktu pengambilan data di lapang (Saleh, 2019).

\section{MATERI DAN METODE Lokasi dan Waktu Penelitian}

Lokasi pengambilan sampel dilakukan di Taman Nasional Komodo yang meliputi 9 stasiun yaitu P. Siaba Besar (KMDC 1), P. Komodo, Gili Lawa (KMDC 2), P. Kelor (KMDC 3), P. Komodo, Loh Gung (KMDC 4), P. Padar (KMDC 5), P. Rinca, Tanjugn Loh Kima (KMDC 6), P. Rinca, Loh Linga (KMDC 7), $P$. Papagarang (KMDC 8), P. Gado (KMDC 9) sebagaimana divisualisasikan pada Gambar 1. Pengambilan sampel foto dilakukan selama 5 bulan dimulai dari 20 Juni - 1 Juli 2019.

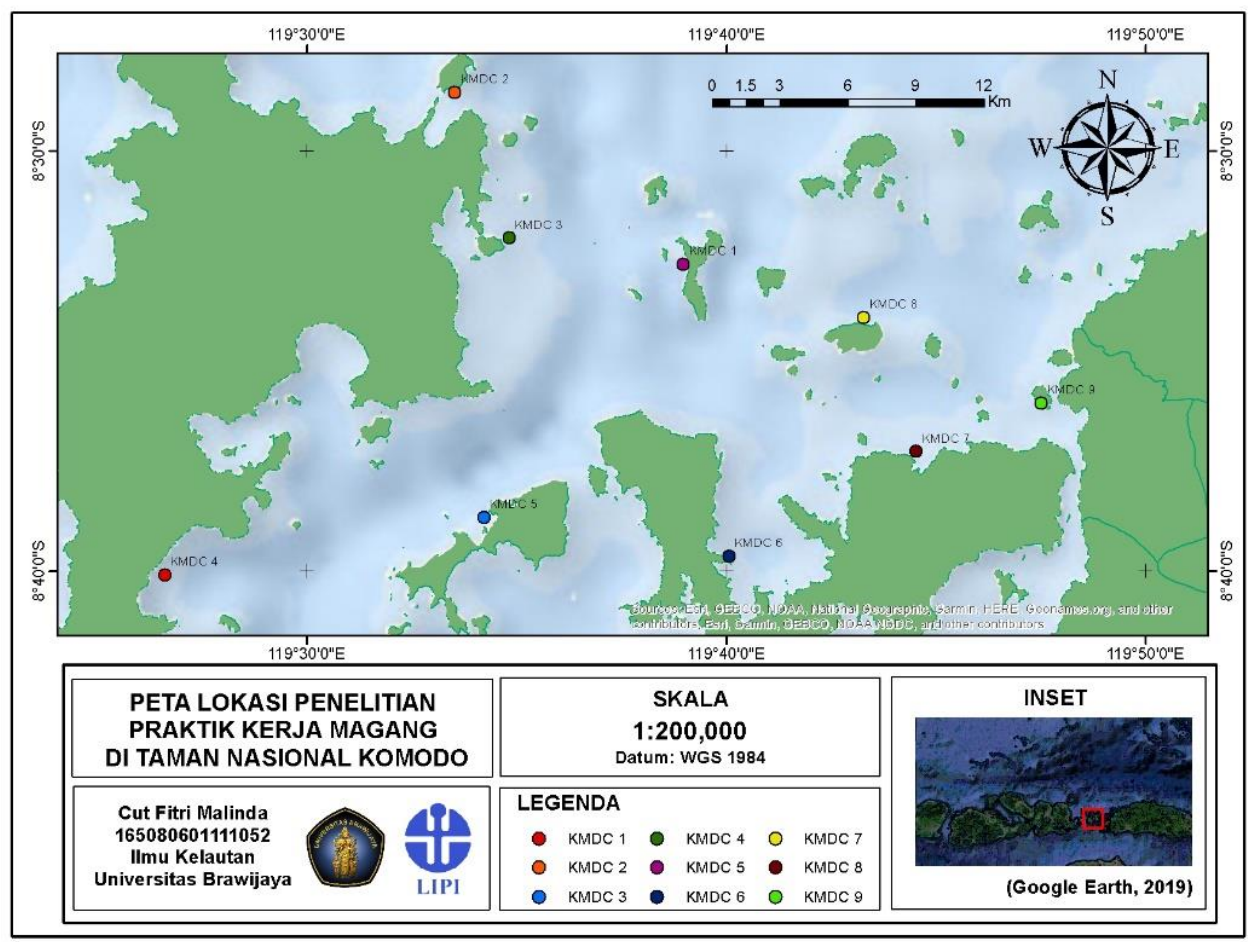

Gambar 1. Peta lokasi penelitian di Taman Nasional Komodo

Persentase tutupan masing-masing kategori biota dan substrat untuk setiap frame foto (Rumus 1) dihitung dengan menggunakan rumus sebagai berikut (Giyanto et al., 2014):

$L=\frac{\Sigma L i}{N} x 100 \%$

(Rumus 1)

Dimana:

$\mathrm{L}=\quad=$ Persentase tutupan sustrat (\%)
$\mathrm{Li} \quad=$ Jumlah titik kategori tersebut

$\mathrm{N} \quad=$ Banyaknya titik acak

Kriteria penilaian ekosistem terumbu karang berdasarkan persentase tutupan karang keras hidup menurut Dahuri (2001), dapat dilihat pada Tabel 1. 
Melinda et al., Analisis Kondisi Kesehatan Terumbu Karang

Tabel 1. Kategori Persentase Tutupan Karang Keras Hidup

\begin{tabular}{lll}
\hline No & $\begin{array}{c}\text { Persentase Tutupan } \\
\text { Karang Keras } \\
\text { Hidup }\end{array}$ & Kategori \\
\hline 1 & $0-25 \%$ & Rusak \\
2 & $25-50 \%$ & Sedang \\
3 & $50-75 \%$ & Baik \\
4 & $75-100 \%$ & Sangat Baik \\
\hline
\end{tabular}

\section{Pengambilan Sampel}

Pengambilan sampel ikan nike dilakukan selama beberapa hari menyesuaikan dengan waktu kemunculan ikan di masing-masing stasiun pada bulan Maret, April, Mei, Juni, dan Juli 2018. Parameter yang diamati adalah frekuensi kemunculan ikan pada setiap periode di setiap stasiun dan ukuran panjang total ikan nike yang tertangkap setiap bulan. Pengambilan sampel dilakukan dengan menggunakan jaring ikan dengan mesh size 0.5 inchi. Pengambilan sampel ikan dilakukan dengan menenggelamkan jaring pada kedalaman 1 - 5 meter dan meletakkan mulut kantong jaring berlawanan dengan arah pergerakan ikan. Jaring dibenamkan di dalam air selama kurang lebih 30 menit dan diangkat saat ikan nike telah masuk melalui bagian mulut kantong dan terperangkap di dalam jaring. Sampel ikan diangkat ke permukaan, dimasukkan ke dalam wadah sampel, diawetkan dengan menggunakan es batu, dan selanjutnya dibawa ke laboratorium untuk diawetkan lebih lanjut dengan formalin $10 \%$. Pengukuran panjang total sampel ikan nike menggunakan alat jangka sorong dengan ketelitian $0.001 \mathrm{~cm}$.

\section{HASIL DAN PEMBAHASAN}

Persentase tutupan bentik menunjukan kondisi habitat bentik di lokasi penelitian. Hasil persentase tutupan kategori bentik dilokasi penelitian dapat ditampilkan pada Tabel 2 . Hasil penelitian memperlihatkan bahwa hanya Lokasi KMDC 2 dalam kategori baik dengan tutupan karang sebesar 58,36\%. Kategori sedang pada lokasi KMDC 1, KMDC 4 dan KMDC 6, adapun lokasi dengan kategori rusak adalah KMDC 3, KMDC 7, KMDC 8 dan KMDC 9.

Tabel 2. Persentase tutupan kategori bentik

Kategori Bentik

Lokasi

\begin{tabular}{|c|c|c|c|c|c|c|c|c|c|}
\hline 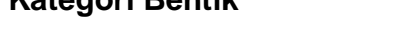 & KMDC 1 & KMDC 2 & KMDC 3 & KMDC 4 & KMDC 5 & KMDC 6 & KMDC 7 & KMDC 8 & KMDC 9 \\
\hline Tutupan Karang (\%) & 49.16 & 58.36 & 22.38 & 32.82 & 22.04 & 27.60 & 20.07 & 5.07 & 26.00 \\
\hline Recently Dead Coral (DC) & 1.61 & 0.78 & 0.40 & 0.27 & 0.21 & 0.20 & 0.13 & 0.00 & 0.07 \\
\hline Dead Coral with Algae & 14.15 & 28.33 & 11.02 & 33.62 & 10.13 & 25.67 & 10.33 & 38.00 & 10.00 \\
\hline Soft Coral (SC) & 0.07 & 2.92 & 28.46 & 8.34 & 39.65 & 0.00 & 8.80 & 5.13 & 0.27 \\
\hline Sponge (SP) & 0.00 & 1.14 & 0.53 & 0.07 & 0.46 & 0.60 & 0.93 & 0.93 & 0.13 \\
\hline Fleshy Seaweed (FS) & 0.07 & 1.07 & 0.00 & 0.00 & 1.06 & 0.20 & 0.00 & 0.00 & 0.00 \\
\hline Others (OT) & 0.63 & 1.07 & 3.47 & 2.80 & 2.2 & 2.07 & 1.00 & 8.07 & 5.20 \\
\hline Rubble (R) & 25.56 & 2.85 & 29.53 & 16.94 & 15.09 & 43.07 & 35.80 & 29.93 & 52.33 \\
\hline Sand (S) & 7.14 & 0.36 & 2.81 & 1.20 & 7.67 & 0.60 & 14.60 & 12.87 & 6.00 \\
\hline Silt (SI) & 0.77 & 3.06 & 0.87 & 3.94 & 0.56 & 0.00 & 8.33 & 0.00 & 0.00 \\
\hline Rock (RK & 0.84 & 0.07 & 0.53 & 0.00 & 0.92 & 0.00 & 0.00 & 0.00 & 0.00 \\
\hline Kondisi Terumbu Karang & Sedang & Baik & Rusak & Sedang & & Sedang & Rusak & Rusak & Rusak \\
\hline
\end{tabular}




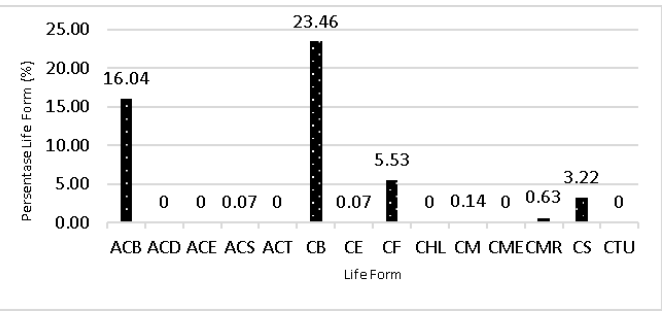

(a)

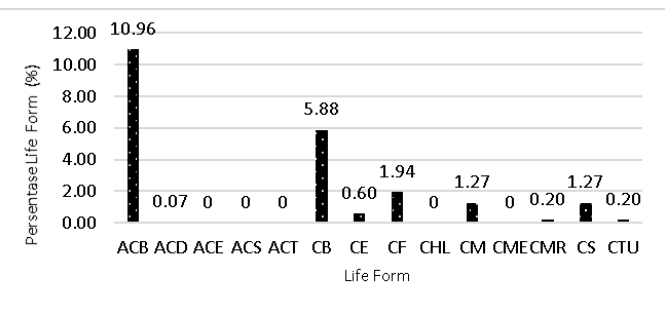

(c)

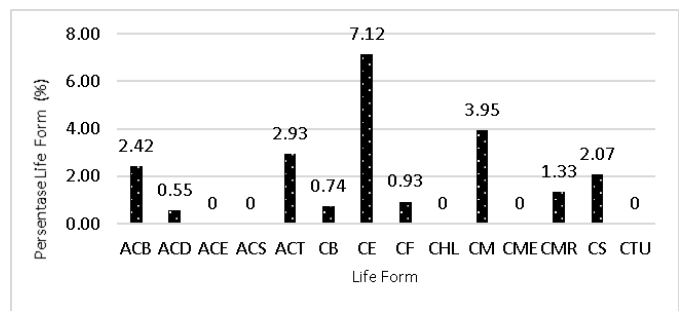

(e)

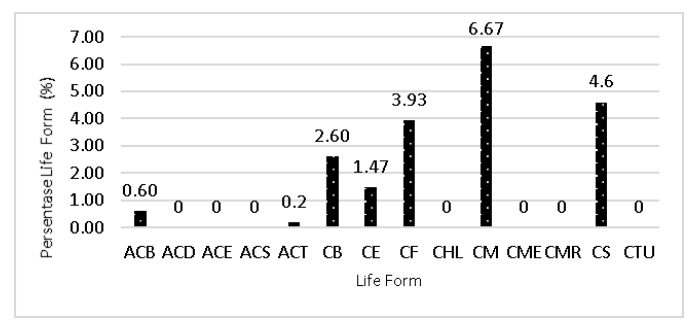

(g)

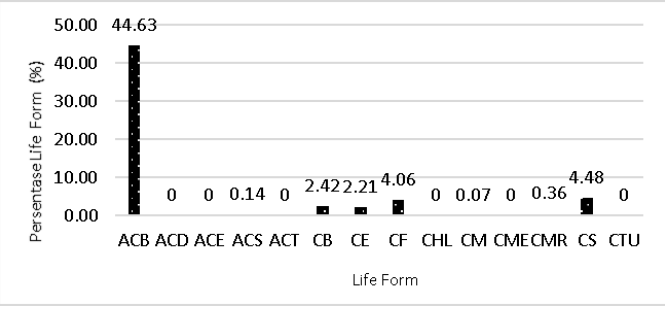

(b)

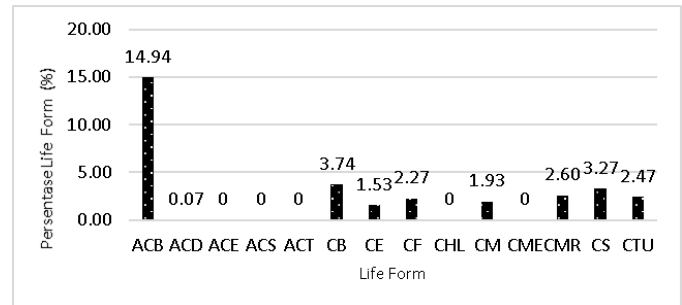

(d)

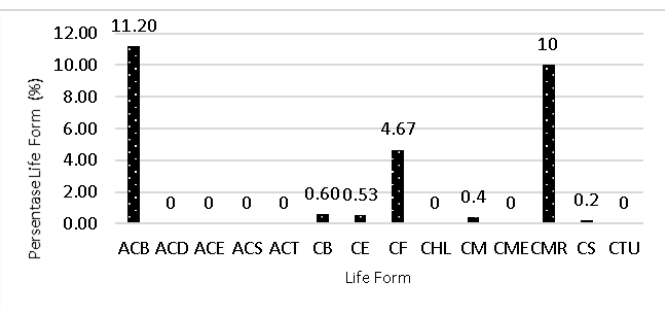

(f)

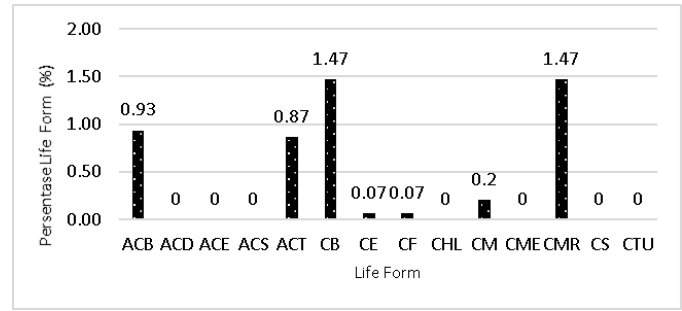

(h)

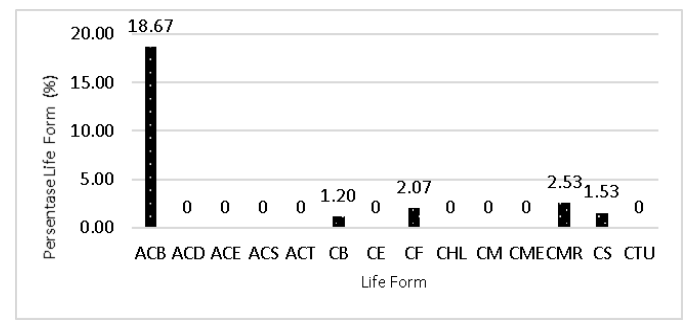

(i)

Keterangan: Acropora Branching (ACB); Acropora Digitate (ACD); Acropora Encrusting (ACE); Acropora Submassive (ACS); Acropora Tabulate (ACT); Coral Branching (CB); Coral Encrusting (CE); Coral Foliose (CF); Coral Heliopora (CHL); Coral Massive (CM); Coral Millepora (CME); Coral Mushroom (CMR); Coral Submassive (CS); Coral Tubipora (CTU).

Gambar 2. Persentase Life Form: (a) KMDC 1; (b) KMDC 2; (c) KMDC 3; (d) KMDC 4; e) KMDC 5; (f) KMDC 6; (g) KMDC 7; (h) KMDC 8; (i) KMDC 9 
Melinda et al., Analisis Kondisi Kesehatan Terumbu Karang

\section{a. Stasiun 1 (KMDC 1)}

Tutupan karang hidup pada stasiun 1 berkisar $49,16 \%$ dan terumbu termasuk dalam kategori cukup. Substrat paling dominan adalah rubble sebesar $25,56 \%$ dan DCA sebesar $14,15 \%$. Berdasarkan gambar 15a, karang didominasi oleh life form CB sebesar $23,46 \%$ dan ACB sebesar $16,04 \%$. Karang bercabang sangat rentan terhadap perubahan kondisi perairan, namun jika kondisi perairan tetap baik, pertumbuhan karang bercabang akan cepat meningkat.

\section{b. Stasiun 2 (KMDC 2)}

Tutupan karang hidup pada stasiun 2 memiliki nilai tutupan paling tinggi dari semua stasiun sebesar $58,36 \%$ dan termasuk dalam kategori baik. Substrat paling dominan adalah DCA sebesar $28,33 \%$ dan sisanya memiliki persentase dibawah 5\%. Berdasarkan gambar $15 \mathrm{~b}$, karang didominasi oleh life form ACB sebesar $44,63 \%$.

\section{c. Stasiun 3 (KMDC 3)}

Tutupan karang hidup pada stasiun 3 sebesar $22,38 \%$ dan termasuk dalam kategori rusak. Substrat paling dominan adalah rubble sebesar $29,53 \%$ dan soft coral sebesar $28,46 \%$. Hal ini sangat memprihatinkan karena terjadinya kompetensi tempat hidup antara karang keras dan soft coral, dimana karang keras tidak dapat mempertahankan tempat hidupnya. Banyaknya rubble juga dapat dijadikan pertimbangan untuk membuat substrat buatan untuk melekatnya larva karang, karena rubble merupakan stuktur substrat yang tidak stabil sehingga kurang tepat untuk dijadikannya tempat perlekatan. Berdasarkan gambar $15 \mathrm{c}$, karang didominasi oleh life form ACB sebesar 10,96\% dan CB sebesar $5,88 \%$.

\section{d. Stasiun 4 (KMDC 4)}

Tutupan karang hidup pada stasiun 4 berkisar $32,82 \%$ dan terumbu termasuk dalam kategori cukup. Substrat paling dominan adalah DCA sebesar $33,62 \%$ dan rubble sebesar $16,94 \%$. Besarnya nilai DCA dibandingkan karang keras pada stasiun 4 menandakan terjadinya bleaching pada masa lampau. Besarnya nilai soft coral sebesar $8,34 \%$ juga perlu diperhatikan. Berdasarkan gambar $15 \mathrm{~d}$, karang didominasi oleh life form ACB sebesar 14,94\% dan CB hanya sebesar 3,74\%.

\section{e. Stasiun 5 (KMDC 5)}

Tutupan karang hidup pada stasiun 5 berkisar $22,04 \%$ dan terumbu termasuk dalam kategori rusak. Substrat paling dominan adalah soft coral sebesar $39,65 \%$ dan rubble sebesar $15,09 \%$. Hal ini cukup memprihatinkan karena kalahnya kompetensi tempat hidup antara karang keras dan soft coral. Banyaknya rubble juga menandakan perlu dibentuknya substrat buatan untuk tempat melekatnya larva karang. Berdasarkan gambar 15e, karang didominasi oleh life form CE sebesar $7,12 \%$ dan life form lain memiliki persentase dibawah $5 \%$.

\section{f. Stasiun 6 (KMDC 6)}

Tutupan karang hidup pada stasiun 6 berkisar $27,60 \%$ dan terumbu termasuk dalam kategori cukup. Substrat paling dominan adalah rubble sebesar $43,07 \%$ dan DCA sebesar $25,67 \%$. Berdasarkan gambar 15f, karang didominasi oleh life form ACB sebesar $11,02 \%$ dan CMR sebesar $10 \%$.

\section{g. Stasiun 7 (KMDC 7)}

Tutupan karang hidup pada stasiun 7 berkisar $20,07 \%$ dan terumbu termasuk dalam kategori rusak. Substrat paling dominan adalah rubble sebesar $35,80 \%$ dan pasir sebesar $11,60 \%$. Hal ini sangat memprihatinkan karena tingginya persentase unstable substrate dan rendahnya stable substrate yaitu DCA sebesar 10,33\%. Berdasarkan gambar $15 \mathrm{~g}$, karang didominasi oleh life form CM sebesar $6,67 \%$ dan CS sebesar $4,6 \%$.

\section{h. Stasiun 8 (KMDC 8)}

Tutupan karang hidup pada stasiun 8 berkisar $5,07 \%$ dimana merupakan persentase karang keras terendah dari semua stasiun dan terumbu termasuk dalam kategori rusak. Substrat paling dominan adalah DCA sebesar $38 \%$ dan rubble sebesar 29,93\%. Berdasarkan gambar $15 \mathrm{~h}$, karang didominasi oleh life form CB dan CMR yang memiliki nilai $1,47 \%$.

\section{i. Stasiun 9 (KMDC 9)}

Tutupan karang hidup pada stasiun 9 berkisar $26 \% \%$ dan terumbu termasuk dalam kategori cukup. Substrat paling dominan adalah rubble sebesar 52,33\% dan DCA sebesar $10 \%$. Berdasarkan gambar 15i, karang didominasi oleh life form ACB sebesar $18,67 \%$ dan life form lain memilik persentase dibawah $3 \%$.l 




Gambar 3. Persentase substrat masing-masing stasiun

Setelah dilakukan pengumpulan data dari 9 titik stasiun, selanjutnya dibuat grafik yang mendeskripsikan masing-masing persentase kode bentik pada masing-masing stasiun. Tutupan karang keras tertinggi terdapat di stasiun 2 sebesar $58,36 \%$, disusul oleh stasiun
1 sebesar 49,16\% dimana masih termasuk dalam kategori Baik. Persentase tutupan karang hidup terendah berada pada stasiun 8 sebesar 5,07\%. Hal ini dikarenakan lokasi dekat dengan pemukiman warga serta perairan yang keruh.

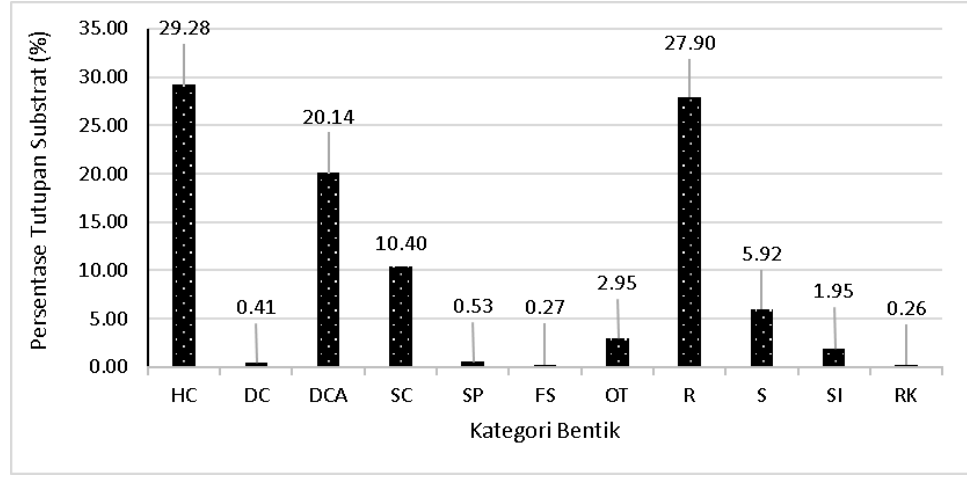

Keterangan: HC (Hard Coral), DC (Dead Coral), DCA (Dead Coral with Algae), SC (Soft Coral), SP

(Sponge), FS (Fleshy Seaweed), OT (Others), R (Rubble), S (Sand), SI (Silt), RK (Rock)

Gambar 4. Persentase substrat seluruh stasiun

Tutupan karang keras di Perairan Komodo memiliki persentase sebesar $29,28 \%$ yang termasuk dalam kategori cukup. Jenis karang hidup yang ditemukan adalah Acropora dan Non Acropora. Selain karang hidup juga ditemukan jenis substrat biotik lainnya yaitu Soft Coral dengan nilai tutupan sebesar $10,4 \% \%$, serta jenis substrat abiotic antara lain adalah Rubble sebesar $34,6 \%$ dan disusul oleh DCA atau karang mati yang ditumbuhi alga sebesar $20,14 \%$. Besarnya unstable substrate berupa rubble sangat memprihatinkan karena sulit bagi larva karang untuk tumbuh.

\section{KESIMPULAN}

Proses identifikasi karang untuk mendapatkan persentase tutupan karang keras dapat menggunakan perangkat lunak CPCe (Coral Point Count with Excel Extension). Tahapan yang harus dilakukan memasukkan foto tiap stasiunnya lalu ditentukan titik secara acak sebanyak 30 titik per fotonya dan mengisi kolom identifikasi sesuai index yang sudah ada. Langkah terakhir yaitu melakukan export data sebanyak 50 data berformat ".cpc" menjadi ".xls". Persentase tutupan karang keras yang didapatkan sebesar 29,28\% di Pulau Komodo yang termasuk dalam kategori Cukup.

\section{UCAPAN TERIMAKASIH}

Penulis mengucapkan terimkasih kepada kedua orang tua dan teman-teman yang senantiasa mendukung dalam pelaksanaan penelitian ini. Bapak Oktiyas Muzaky Luthfi ST., 
M.Sc. dan Tri Aryono Hadi, S.Si., M.Si yang telah membimbing serta memberikan saran dan masukkan kepada penulis.

\section{DAFTAR PUSTAKA}

Dahuri, R. (2001). Pengelolaan Sumberdaya Wilayah Pesisir dan Lautan secara Terpadu. Pradnya Paramita. Jakarta.

Giyanto, Manuputty, A. E., Abrar, M., Siringoringo, R. M., Suharti, S. R., Wibowo , K., et al. (2014). Panduan Monitoring Kesehatan Terumbu Karang. Jakarta: CTI - LIPI.

Hadi, T. H., Giyanto, Prayudha, B., Hafizt, M., Budiyanto, A., \& Suharsono. 2018. Status Terumbu Karang Indonesia 2018. Jakarta: Puslit Oseanografi - LIPI.

Saleh, A. (2019, April 16). Retrieved from Doc Player: https://docplayer.info. 